\title{
SGK-1 protects kidney cells against apoptosis induced by ceramide and TNF-a
}

\author{
D Pastore', D Della-Morte ${ }^{1,2}$, A Coppola ${ }^{1}$, B Capuani ${ }^{1}$, MF Lombardo ${ }^{1}$, F Pacifici ${ }^{1}$, F Ferrelli', R Arriga ${ }^{1}$, C Mammi ${ }^{3}$, M Federici ${ }^{1,4}$, \\ A Bellia ${ }^{1,4}$, N Di Daniele ${ }^{1,4}$, M Tesauro ${ }^{1,4}$, G Donadel ${ }^{1}$, D Noto ${ }^{5}$, P Sbraccia ${ }^{1,4}$, G Sconocchia ${ }^{6}$ and D Lauro ${ }^{\star, 1,4}$
}

Ceramide regulates several different cellular responses including mechanisms leading to apoptosis. Serum- and glucocorticoidinducible protein kinase (SGK)-1 is a serine threonine kinase, which activates survival pathways in response to stress stimuli. Recently, we demonstrated an anti-apoptotic role of SGK-1 in human umbilical endothelial cells treated with high glucose. In the present study, since ceramide induces apoptosis by multiple mechanisms in diabetes and its complication such as nephropathy, we aimed to investigate whether SGK-1 may protect even against apoptosis induced by ceramide in kidney cells. Human embryonic kidney (HEK)-293 cells stable transfected with SGK-1 wild type (SGK-1wt) and its dominant negative gene (SGK-1dn) have been used in this study. Apoptotic stimuli were induced by $\mathrm{C}_{2}$-ceramide and TNF- $\alpha$ to increase endogenous synthesis of ceramide. Upon activation with these stimuli, SGK-1wt transfected cells have a statistically significant reduction of apoptosis compared with SGK-1dn cells $(P<0.001)$. This protection was dependent on activation of caspase-3 and Poly-ADP-ribosepolymerase-1 (PARP-1) cleavage. SGK-1 and AKT-1 two highly homologous kinases differently reacted to ceramide treatment, since SGK-1 increases in response to apoptotic stimulus while AKT-1 decreases. This enhancement of SGK-1 was dependent on p38-mitogen-activated-protein kinases (p38MAPK), cyclic-adenosine-monophosphate/protein kinase A (cAMP/PKA) and phosphoinositide-3-kinase (PI3K) pathways. Especially, by using selective LY294002 inhibitor, we demonstrated that the most involved pathway in the SGK-1 mediated process of protection was PI3K. Treatment with inhibitor of SGK-1 (GSK650394) significantly enhanced TNF- $\alpha$-dependent apoptosis in HEK-293 cells overexpressing SGK-1wt. Caspase-3, -8 and -9 selective inhibitors confirmed that SGK-1 reduced the activation of caspase-dependent apoptosis, probably by both intrinsic and extrinsic pathways. In conclusion, we demonstrated that in kidney cells, overexpression of SGK-1 is protective against ceramide-induced apoptosis and the role of SGK-1 can be potentially explored as a therapeutic target in conditions like diabetes, where ceramide levels are increased.

Cell Death and Disease (2015) 6, e1890; doi:10.1038/cddis.2015.232; published online 17 September 2015

Apoptosis is a programmed death of cells that has an important role in maintenance of tissue homeostasis by eliminating unneeded cells. Pathways associated with regulation of apoptosis have been demonstrated to contribute in pathophysiology of several diseases like cancer, degenerative diseases, diabetes mellitus (DM) and its associated complications, such as nephropathy. ${ }^{1}$ Among the molecular mechanisms involved in the apoptotic processes, ceramide have a pivotal role. ${ }^{2,3}$ Sphingolipid ceramide are effector molecules that activate intracellular cascade signalling finally resulting in an anti-proliferative response and apoptosis. ${ }^{4}$ The generation of endogenous ceramide is induced by noxious stimuli such as UVA ${ }^{5}$ and proinflammatory cytokines (e.g., TNF- $a$ ), ${ }^{6}$ which promote the release of ceramide from sphingomyelin and/or by the ' $d e$ novo' synthesis from palmitate. ${ }^{7}$

An enhancement of cellular ceramide leads to reduced activation of insulin signalling and this alteration is characteristic of type 2 diabetic (T2D) patients. ${ }^{8-10}$ Ceramide induces apoptosis by multiple mechanisms, such as inhibition of AKT-1 and activation of extrinsic and intrinsic apoptotic pathways. ${ }^{11}$ These pathways converge on the cleavage of caspase- 3 and result in DNA fragmentation, degradation of cytoskeleton and nuclear proteins, and formation of apoptotic bodies including

\footnotetext{
${ }^{1}$ Laboratory of Molecular Medicine, Department of Systems Medicine, University of Rome Tor Vergata, Rome, Italy; ${ }^{2}$ IRCCS San Raffaele Pisana, Rome, Italy; ${ }^{3}$ Laboratory of Cardiovascular Endocrinology, Istituto di Ricovero e Cura a Carattere Scientifico (IRCCS), San Raffaele Pisana, Rome, Italy; ${ }^{4}$ Department of Medicine, University Hospital 'Fondazione Policlinico di Tor Vergata', Rome, Italy; ${ }^{5}$ Department of Internal Medicine and Biomedical Specialist (DIBIMIS), University of Palermo, Palermo, Italy and ${ }^{6}$ Department of Biomedicine, Institute of Translational Pharmacology, National Research Council, Rome, Italy

${ }^{*}$ Corresponding author: D Lauro, Department of Systems Medicine, University of Rome Tor Vergata, Montpellier Street 1, Rome 00133 , Italy; Tel: +39 6 20904666; Fax: +396 20904668. E-mail: d.lauro@med.uniroma2.it

Abbreviations: $\mathrm{C} 2, \mathrm{C}_{2}$-ceramide; $\mathrm{C} 6, \mathrm{C}_{6}$-ceramide; cAMP, cyclic adenosine monophosphate; C2-Dihy, $\mathrm{C}_{2}$-dihydroceramide; CTRL, control; DM, diabetes mellitus; DMSO, dimethyl sulphoxide; ENaC, epithelial $\mathrm{Na}^{+}$channel; FB1, Fumonisin B1; GC/MS, gas chromatography/mass spectrometry; GLUT-1, glucose transporter 1; GSK, GSK650394; HEK-293, human embryonic kidney; HUVEC, human umbilical vein endothelial cells; Ins, insulin; IS, internal standard; NDRG1, N-myc downstream regulated gene 1; NO, nitric oxide; p38, P38 mitogen-activated protein kinases; PARP-1, poly (ADP-ribose) polymerase-1; PBS, phosphate buffer saline; PDK-1, phosphoinositide-dependent kinase-1; PH, Pleckstrin homology domain; PI, propidium iodide; PI3K, phosphoinositide-3 kinase; PKA, protein kinase A; PKB, protein kinase B; ROS, reactive oxygen species; SDS-PAGE, sodium dodecyl sulphate-polyacrylamide gel electrophoresis; SGK-1, serum and glucocorticoid inducible protein kinase; SGK-1dn, SGK-1 dominant negative; SGK-1wt, SGK-1 wild type; SIM, single ion monitoring; siRNA, short interfering RNA; SPT, serine palmitoyl transferase; T2D, type 2 diabetes; TMS, trimethylsilyl; TNF- $\alpha$, tumour necrosis factor-alpha; WB, western blot

Received 24.5.2015; revised 25.6.2015; accepted 06.7.2015; Edited by G Melino
} 
DNA fragments ('DNA ladder'). ${ }^{12}$ Caspases, a family of cysteine proteases, are expressed in cells as inactive procaspase precursors. ${ }^{13}$ Initiator caspases, such as 8 and 9 , are activated by an autocatalytic process induced by the interaction of an initiator caspase, via its pro-domain, with its adaptor protein. Then, initiator caspases cleave the precursor forms of effectors caspases, like caspase-3, which execute apoptosis by cleaving cellular proteins. ${ }^{14}$ Caspases 3 and 7 cleave PARP-1 into two fragments, $\sim$ p89 and $\sim$ p24, separating DNA binding from the catalytic domain inducing PARP-1 inactive. ${ }^{15}$

Serum and glucocorticoid-inducible kinase-1 (SGK-1) is a 49-kDa AGC family serine threonine protein kinase, displaying similarity (54\% homology) throughout its catalytic domains with PKB/AKT-1, however lacking of pleckstrin homology domain $(\mathrm{PH})$, presents in AKT-1. ${ }^{16} \mathrm{SGK}-1$ stimulates a variety of ion channels, transporters and transcription factors, which can modulate kidney function, blood pressure and insulin action, suggesting its role in the pathophysiology of DM and its complications like diabetic kidney disease. ${ }^{17-19}$ Moreover, SGK-1 has been directly involved in the regulation of glucose uptake. ${ }^{20}$ SGK-1 has been also implicated in the activation of cellular survival pathways since several evidence outline how SGK-1 overexpression and activation inhibit cell apoptosis in mammalian cells, becoming considered a pro-survival kinase. ${ }^{21}$ Furthermore, we showed as SGK-1 also modulates endothelial function by decreasing apoptosis and increasing insulin mediated nitric oxide (NO) production in basal conditions and after oxidative stress damage in endothelial cells. $^{19}$

Therefore, in the present in vitro study, we sought to investigate the possible protective role of SGK-1 in the kidney cells against apoptotic damage induced by ceramide.

\section{Results}

SGK-1 activity is higher in SGK-1wt cells. Human embryonic kidney (HEK) 293 cells transfected with SGK-1wt and SGK-1dn (dominant negative) constructs were utilized for this study (Supplementary Figure S1). Expression of SGK-1 protein was evaluated in HEK-293 cells transfected with pcDNA3 (Mock), SGK-1wt and SGK-1dn constructs (Figure 1a). We aimed to measure the SGK-1 activity in cell constructs to ensure that transfected cells were biological active. To measure SGK-1 activity, we evaluated the phosphorylation of NDRG1 (N-myc downstream regulated gene 1), a well-established substrate of SGK-1, ${ }^{22}$ in cells transfected with pcDNA3 (Mock), SGK-1wt and SGK-1dn in the presence or absence of insulin for $30 \mathrm{~min}$. Since SGK-1 phosphorylates NDRG1 in Thr346, Thr356, Thr366 and Ser330, we evaluated Thr346 (antibody that cross-reacts with Thr356 and Thr366) and Ser330 phosphorylation site. We found that the phosphorylation of NDRG1 was significantly higher in SGK-1wt cells in the presence and/or absence of insulin compared with SGK-1dn $(P<0.001)$ and almost absent in Mock (Figures $1 \mathrm{~b}$ and $\mathrm{d}$ ) cells. These results suggest that SGK-1 overexpressed in our wt group is biologically active and present higher activity of this kinase compared with dn cells.

SGK-1 wt protects against apoptosis induced by $\mathbf{C}_{\mathbf{2}}$-ceramide. HEK-293 cells were treated with a short chain of synthetic Ceramide $\left(\mathrm{C}_{2}\right.$-ceramide $)$ and the possible noxious effects of $\mathrm{C}_{2}$-ceramide were compared with $\mathrm{C}_{2}$-dihydroceramide $\left(\mathrm{C}_{2}\right.$-Dihy, inactive analogue) treatments. Cells treated with dimethyl sulphoxide (DMSO, vehicle) and/or $\mathrm{C}_{2}$-Dihy maintained normal morphology, whereas cells treated with a

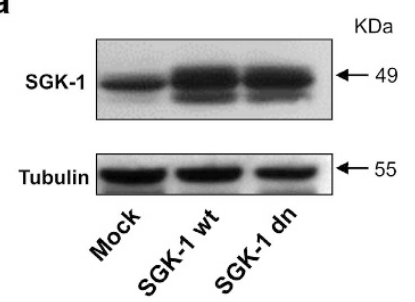

C

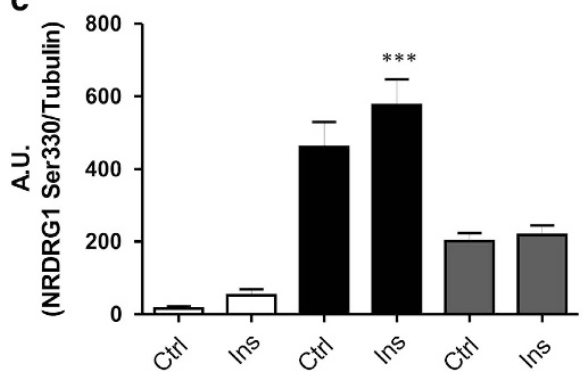

b

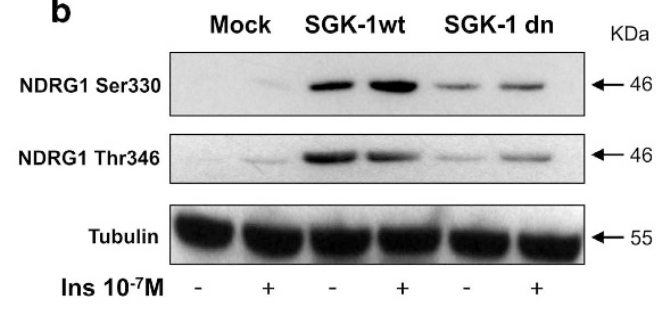

d

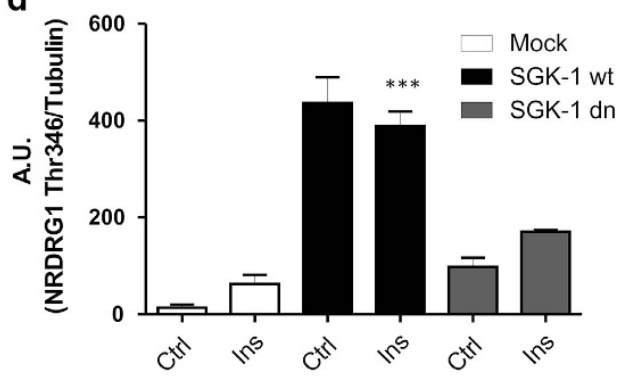

Figure 1 Activity of SGK-1 in HEK-293 cells. Expression of SGK-1 protein is evaluated in HEK-293 cells stable transfected with pcDNA3 (Mock), SGK-1wt and SGK-1dn constructs. $100 \mu \mathrm{g}$ of total extract protein was analysed by western blot using anti-SGK-1 antibody. Tubulin was used as a loading control (a). Activity of SGK-1 in HEK-293 cells stable transfected with pcDNA3 (Mock), SGK-1wt and SGK-1dn constructs was detected through NDRG1 phosphorylation levels in Thr346 and Ser330 in the presence and absence of Insulin $10^{-7} \mathrm{M}$ for $30 \mathrm{~min}$ using western blot analysis. Tubulin was used as a loading control. (b) A quantification of three independent experiments by scanning densitometry is shown in (c and $\mathbf{d}$ ), ${ }^{* \star *} P<0.001$ Ins (SGK-1 wt) versus Ctrl and Ins (Mock), and Ctrl and Ins (SGK-1 dn); $N=3$. Results are expressed as means \pm S.D. 

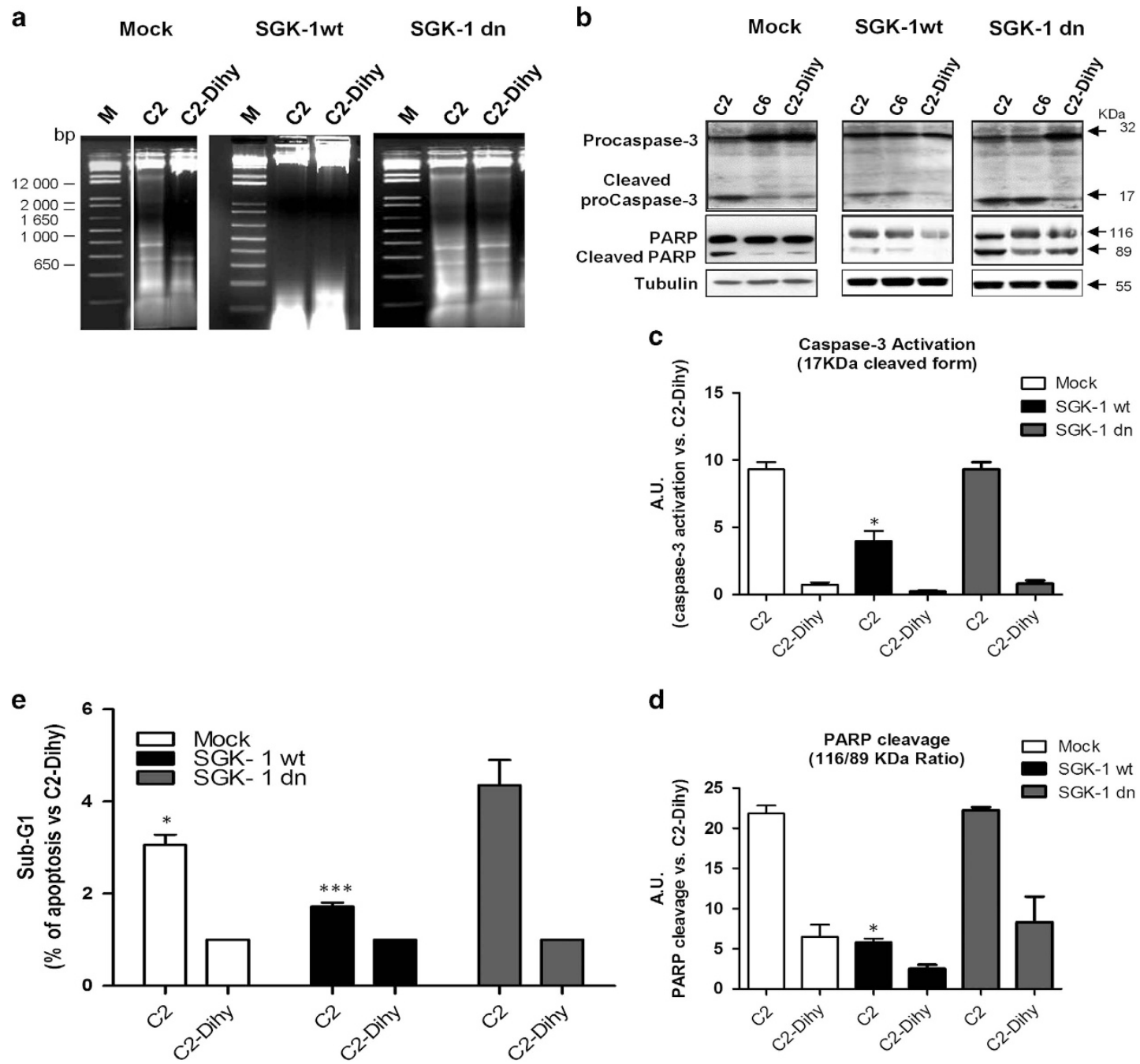

d

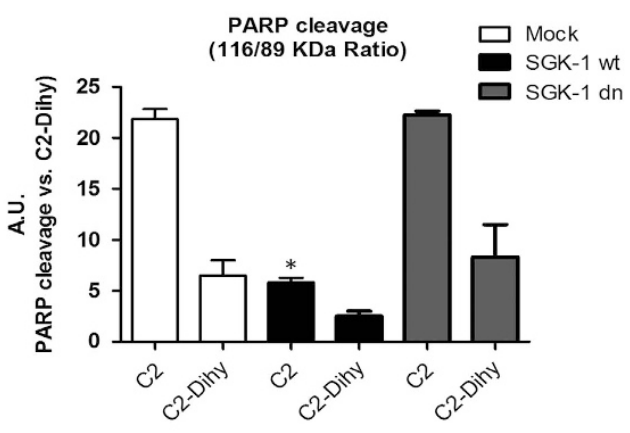

Figure 2 SGK-1wt overexpression protects by ceramide-induced apoptosis. HEK-293 cells stable transfected with pcDNA3 (Mock), SGK-1wt and SGK-1dn constructs were stimulated with $50 \mu \mathrm{M} \mathrm{C}_{2}$-ceramide and $\mathrm{C}_{2}$ dihydroceramide $\left(\mathrm{C}_{2}\right.$-Dihy) used as a negative control. Apoptosis was induced with $\mathrm{C}_{2}$-ceramide for $48 \mathrm{~h}$ and apoptosis levels were detected using DNA fragmentation analysis. The DNA was extracted and analysed on 1.5\% Agarose gel (M: marker 1Kb plus) (a). The apoptotic effect of $\mathrm{C}_{2}$-ceramide versus $\mathrm{C}_{2}$-Dihy was measured in HEK-293 cells transfected with Mock, SGK-1wt and SGK-1dn by caspase-3 activation and by PARP-1 cleavage (b-d). HEK-293 cells stable transfected with Mock, SGK-1wt and SGK-1dn were stimulated with $50 \mu \mathrm{M} \mathrm{C}_{2}$-ceramide, $\mathrm{C}_{6}$-ceramide and $\mathrm{C}_{2}$-Dihy. After $48 \mathrm{~h}$ of treatment with ceramide, the cells were lysed and $100 \mu \mathrm{g}$ of total proteins was separated on SDS-PAGE and immunoblotted with specific antibodies. Active caspase-3 was identified with antibodies specific for the $17 \mathrm{KDa}$ cleaved fragment while procaspase-3 was identified as $32 \mathrm{KD}$ a protein band. Active, full-length PARP-1 was identified with antibodies specific for the 116-KDa fragment, while cleaved PARP-1 was identified as $89 \mathrm{KD}$ a protein band. Tubulin was used as a loading control. The blots shown are representative of the three independent experiments (b). A quantification of three independent experiments by scanning densitometry is shown in (c and d), ${ }^{*} P<0.05 \mathrm{C} 2$ (SGK-1wt) versus $\mathrm{C} 2$ (Mock and SGK-1 dn); $N=3$. The effect of $\mathrm{C}_{2}$-ceramide in HEK-293 cells stable transfected with Mock, SGK-1wt and SGK-1dn was compared by FACS analysis. A representative histogram of apoptosis versus $\mathrm{C}_{2}$-Dihy is shown in (e), ${ }^{* * *} P<0.001$ C2 (SGK-1wt) versus C2 (Mock and SGK-1dn), ${ }^{*} P<0.05$ C2 (Mock) versus C2 (SGK-1dn); $N=3$. Results are expressed as means \pm S.D.

$\mathrm{C}_{2}$-ceramide were rounded, shrunken and partially detached from flask support (Supplementary Figure S2), suggesting as these cells are more susceptible to apoptosis. The intra-nucleosomal DNA fragmentation was measured with DNA-ladder analysis showing higher DNA fragmentation in Mock and SGK-1 dn cells after treatment with $\mathrm{C}_{2}$-ceramide compared with SGK-1wt cells group (Figure 2a).

In our model, $\mathrm{C}_{2}$-ceramide but not $\mathrm{C}_{2}$-Dihy induced caspase- 3 activation (revealed by the presence of $17 \mathrm{KDa}$ protein band as active cleaved form) and PARP-1 cleavage (revealed by presence of $89 \mathrm{KDa}$ protein band) (Figure 2b). To further confirm our result, we tested $\mathrm{C}_{6}$-ceramide as analogue to $\mathrm{C}_{2}$-ceramide. For its conformation, $\mathrm{C}_{6}$-ceramide has lower solubility; indeed its effects on caspase- 3 activation were reduced compared with $\mathrm{C}_{2}$-ceramide treatment in Mock and SGK-1 wt cells, but not in SGK-1 dn cells (Figure 2b). The activation of Caspase-3 and subsequent PARP-1 cleavage were reduced in SGK-1wt cells stimulated with $\mathrm{C}_{2}$-ceramide compared with Mock and SGK-1dn cells $(P<0.05)$ (Figures $2 \mathrm{~b}$ and $\mathrm{d})$, suggesting that ceramide-mediated apoptosis is a SGK-1-dependent process. FACS analysis confirmed that SGK-1wt cells have a significant reduction in apoptotic levels compared to cell transfected with SGK-1dn, and empty vector constructs of 2.5 - and 2 -fold $(P<0.001)$, respectively (Figure 2e). Plots of flow-cytometry experiments are reported in Supplementary Figure S3. 

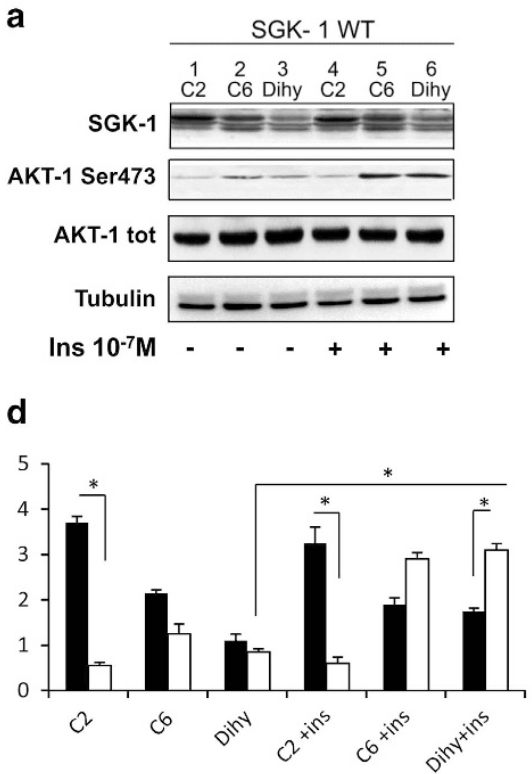

SGK-1 P/Tubulin

AKT-1 Ser 473/AKT-1 tot/Tubulin b

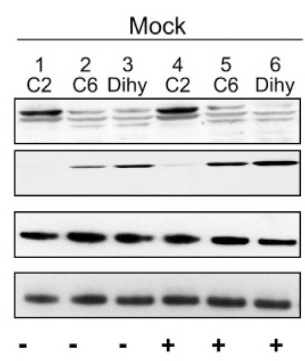

e

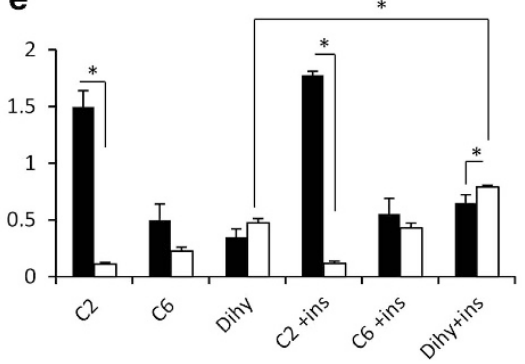

c

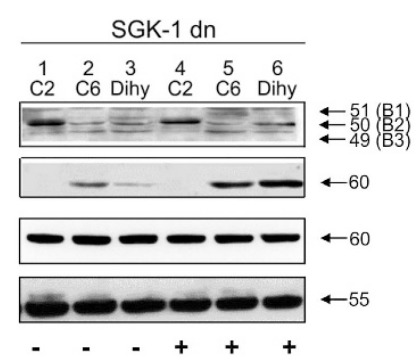

f

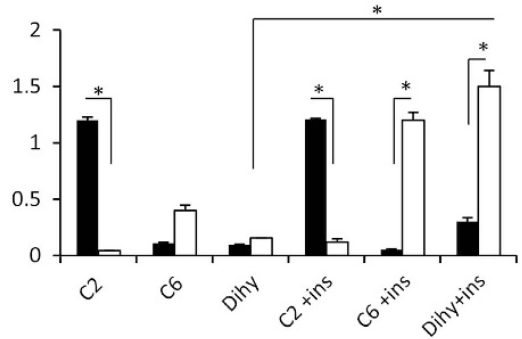

Figure $3 \quad \mathrm{C}_{2}$-ceramide but not $\mathrm{C}_{2}$-dihydroceramide activates SGK-1 protein and inhibits AKT-1 phosphorylation and expression. HEK-293 SGK-1wt (a), Mock (b) and SGK-1dn (c) transfected cells were treated with $50 \mu \mathrm{M} \mathrm{C}_{2}$-ceramide (lanes 1 and 4), $\mathrm{C} 6$ (lanes 2 and 5) and $\mathrm{C}_{2}$-Dihy (lanes 3 and 6 ), in the presence or absence of insulin $10^{-7} \mathrm{M}$ for $48 \mathrm{~h}$. Proteins were analysed by western blot using anti-SGK-1, anti-AKT-1 phospho-Ser-473, anti-AKT-1 total and anti-Tubulin to detect proteins expression and phosphorylation $(\mathbf{a}-\mathbf{c})$. Tubulin was used as a loading control. Western blot analysis and representative densitometry of at least three independent experiments $(\mathbf{d}-\mathbf{f}),{ }^{*} P<0.05$; $N=3$. Results are expressed as means \pm S.D.

These results confirm the protective role of SGK-1 in response to $\mathrm{C}_{2}$-ceramide-induced apoptosis.

$\mathrm{C}_{2}$-ceramide increases SGK-1 and decreases AKT-1 activation. SGK-1 protein levels and activation were measured in response to $\mathrm{C}_{2}$-ceramide, $\mathrm{C}_{6}$-ceramide and $\mathrm{C}_{2}$-Dihy. In these experiments, AKT-1 expression and activation levels were also evaluated, since SGK-1 and AKT-1 have similar protective effects after induction of apoptosis. ${ }^{23}$

Transfected cells were incubated with $\mathrm{C}_{2}$-ceramide, $\mathrm{C}_{6}$-ceramide or $\mathrm{C}_{2}$-Dihy (negative control), with or without insulin treatment for $30 \mathrm{~min}$ to detect SGK-1 and AKT-1 activation. Different SGK-1 protein bands (B1:51, B2:50, $\mathrm{B} 3: 49 \mathrm{KDa}$ ) were identified as already reported in the literature. ${ }^{24}$ The hyperphosphorylated form of SGK-1 can be considered the slower migrating protein band (B1), while the faster migrating species represent the hypophosphorylated proteins (B2 and B3). ${ }^{24}$ As shown in SGK-1 wt cells (Figure 3), treatment with $\mathrm{C}_{2}$-ceramide and $\mathrm{C}_{6}$-ceramide increased SGK-1 phosphorylation, while $\mathrm{C}_{2}$-ceramide decreased AKT-1 phosphorylation (Ser473) compared to treatment with $\mathrm{C}_{2}$-Dihy $(P<0.05)$. Furthermore, in the presence of $\mathrm{C}_{2}$-ceramide, SGK-1 and AKT-1 phosphorylation was independent of insulin treatment (Figures $3 a$ and d). These results were confirmed in Mock cells even if the protein signal of SGK-1 was lower since SGK-1 in these cells is less expressed (Figures $3 b$ and e). In the SGK-1dn cells, $C_{2}$-ceramide induced synthesis of SGK-1 protein band (B2) with not increased levels of SGK-1 phosphorylation (B1) (Figures $3 c$ and f). The effect of
$\mathrm{C}_{2}$-ceramide in AKT-1 was even more evident by almost abolishing the protein signal either in the presence or in the absence of insulin treatment (Figure 3). Present results suggest different roles of SGK-1 and AKT-1 in response to $\mathrm{C}_{2}$-ceramide independently of insulin treatment. Therefore, we may conclude that the protective action in response to ceramide is due to SGK-1 activation.

Increased SGK-1 activity and expression is mediated by PKA, p38 and PI3K signalling pathways. To further investigate the SGK-1 protective role against apoptosis, we analysed specific pathways regulating SGK-1 expression and activity, which include p38/MAPK, cAMP/PKA and PI3K, ${ }^{24,25}$ using selective inhibitors SB202190, H-89 and LY294002, respectively. ${ }^{24-27}$ SGK-1wt cells were treated with inhibitors for 30 min and then cells were stimulated with $\mathrm{C}_{2}$-ceramide or $\mathrm{C}_{2}$-Dihy (Supplementary Figure $\mathrm{S} 1$ ). In the same experimental conditions, insulin effects were tested to avoid possible bias, and no additional or different modulations among treated groups have been found (data not shown). SGK-1 expression was reduced in the presence of SB202190 $(P<0.05)$, H89 $(P<0.01)$ and LY294002 $(P<0.01)$ after $\mathrm{C}_{2}$-ceramide stimulation (Figures $4 \mathrm{a}$ and $\mathrm{b}$ ). Further, confirming the role of $\mathrm{C}_{2}$-ceramide, the treatment with $\mathrm{C}_{2}$ Dihy, with or without the three different inhibitors, had no effect on the SGK-1 expression (Figures $4 a$ and $b$ ). We also calculated (ratio $\mathrm{C}_{2} / \mathrm{C}_{2}$-Dihy, $\mathrm{C}_{2} / \mathrm{C}_{2}$ Inhibitors) the decreased expression of SGK-1 in response to $\mathrm{C}_{2}$-ceramide in the presence of selective inhibitors, with the aim to understand 

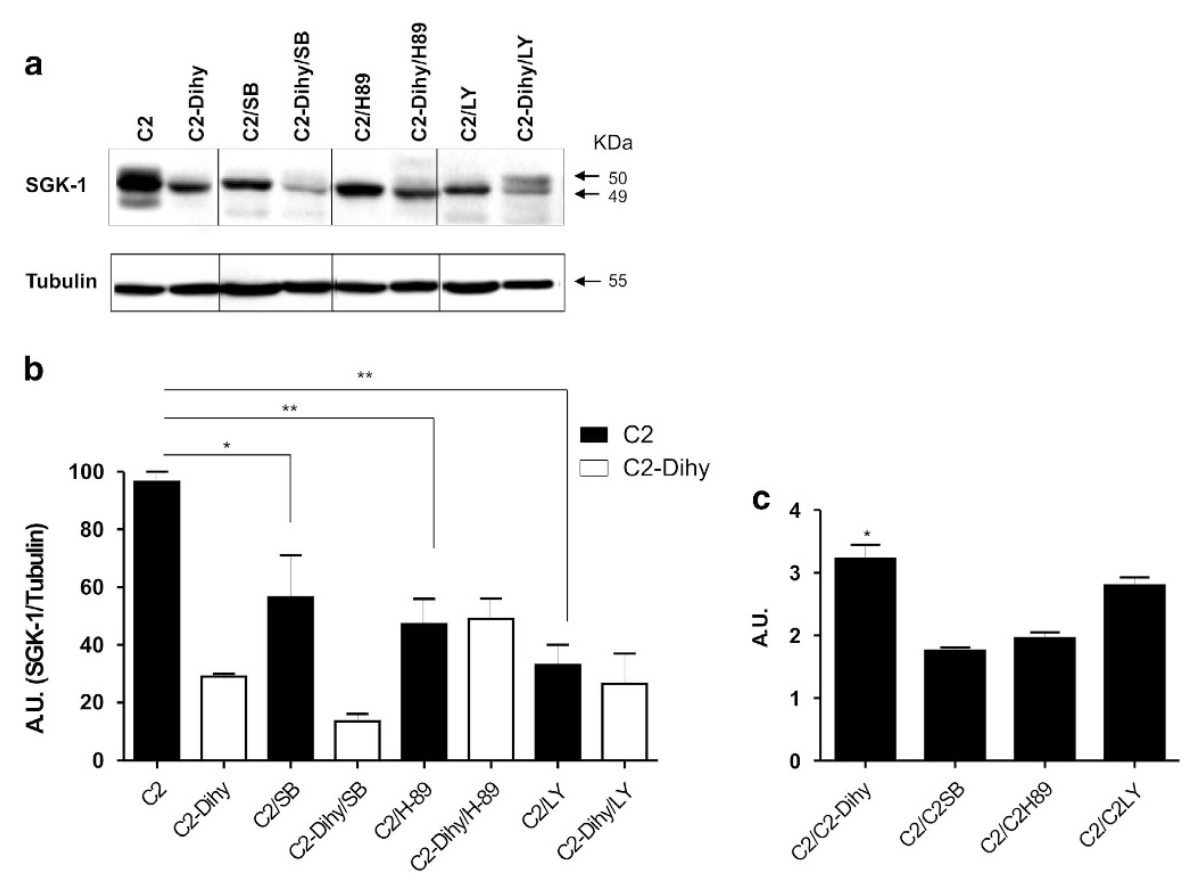

Figure $4 \quad \mathrm{C}_{2}$-ceramide-mediated SGK-1 expression is activated via p38/MAPK, CAMP/PKA and PI3K pathways. HEK-293 cells stably transfected with SGK-1wt were treated with $\mathrm{C}_{2}$-ceramide $(50 \mu \mathrm{M}), \mathrm{C}_{2}$-Dihy $(50 \mu \mathrm{M})$, SB202190 $(10 \mu \mathrm{M})$ (p38 inhibitor), H-89 (10 $\left.\mu \mathrm{M}\right)$ (PKA inhibitor) and LY294002 (30 $\left.\mu \mathrm{M}\right)$ (PI3K inhibitor). After $48 \mathrm{~h}, \mathrm{SGK}-1$ expression was evaluated with antibodies specific for SGK-1. The protein levels of SGK-1 were compared with Tubulin levels. Results were confirmed in at least three separate experiments. Blots shown are representative of three independent experiments. Tubulin was used as a loading control (a). A quantification of three independent experiments by scanning densitometry is shown in (b) ( $\left.{ }^{*} P<0.05,{ }^{* *} P<0.01 ; N=3\right)$. The Ratio between $\mathrm{C}_{2}$-ceramide (C2) and C2-Dihy or $\mathrm{C}_{2}$-ceramide with inhibitors (C2/C2SB, C2/C2H89, C2/ $\mathrm{C} 2 \mathrm{LY}$ ) was evaluated (c), ${ }^{*} P<0.05, \mathrm{C} 2 / \mathrm{C} 2$-Dihy versus $\mathrm{C} 2 / \mathrm{C} 2 \mathrm{SB}, \mathrm{C} 2 / \mathrm{C} 2 \mathrm{H} 89 ; N=3$. Results are expressed as means $\pm \mathrm{S} . \mathrm{D}$.

which is the cell pathway more involved after $\mathrm{C}_{2}$-ceramide treatments (Figure 4c). The higher difference in SGK-1 expression was found following treatment with $\mathrm{C}_{2}$-ceramide and LY inhibitor, suggesting a principal role of PI3K pathway in modulation of SGK-1 levels.

SGK-1 protects against apoptosis induced by TNF- $a$. Since TNF- $a$ stimulus increases the level of cellular ceramide $^{28,29}$ transfected cells were treated with TNF- $a$ for 72 h (Supplementary Figure S1). SGK-1wt have a significant lower percentage of apoptosis compared with Mock and SGK-1dn groups after TNF- $a$ stimulation $(\sim 2$-fold, $P<0.05)$ (Figure 5a). The activation of 'de novo' ceramide synthesis leads to ceramide-induced apoptosis. Therefore, we also investigated whether inhibition of this process protects cells from ceramide-induced apoptosis. HEK-293 were treated with or without Fumonisin B1 (FB1), an inhibitor of ceramide synthase, and then stimulated with TNF-a (Supplementary Figure S1). In SGK-1dn and Mock cells, the treatment with FB1 30 min before TNF- $a$ exposure induced a significant reduction of apoptosis, suggesting that it was mediated, at least in part, by 'de novo' ceramide synthesis (Figure 5a). FB1 alone did not induce any significant effect in HEK-293 (data not shown).

To confirm our hypothesis, we measured levels of endogenous ceramide after TNF- $a$ treatment. Elevated levels of ceramide were observed in Mock and SGK-1dn cells, while in SGK-1wt cells a significant reduction of ceramide with respect to Mock and SGKdn was found $(P<0.0001)$. TNF- $a$-treated cells were characterized by production of $\mathrm{C}_{16}$-ceramide. $\mathrm{FB} 1$ treatment induced a significant TNF- $a$-dependent reduction of $\mathrm{C}_{16}$-ceramide in all transfected groups (Figure $5 \mathrm{~b}$ ). Apoptotic process was confirmed measuring PARP-1 cleaved levels (Supplementary Figure S4). Indeed, SGK-1 wt cells were more resistant to apoptosis after TNF- $a$ treatments versus Mock $(P<0.05)$, and SGK-1dn cells $(P<0.05)$.

Selective SGK-1 inhibitor blunts apoptotic protection. To test whether SGK-1 is pivotal in the protection against apoptosis induced by ceramide, we treated the three groups with a selective inhibitor of SGK-1 activity (GSK650394) 60 min before TNF- $a$ stimulation. ${ }^{30}$ After $72 \mathrm{~h}$, cells were analysed by FACS (Supplementary Figure S1). SGK-1wt cells after TNF- $a$ stimulation showed reduced levels of apoptosis compared with SGK-1dn $(P<0.05)$ or Mock cells $(P<0.05)$ (Figures $6 \mathrm{a}$ and b). After treatment with GSK650394, no significant differences in apoptotic levels were present either in Mock or in SGK-1dn cells, while the inhibitor significantly blunted the protection against apoptosis in the SGK-1wt $(P<0.01)$ cells, suggesting a pivotal role of this kinase in protection against ceramide insult.

TNF- $\boldsymbol{a}$ induces apoptosis through caspase-3-dependent pathways. We aimed to investigate whether caspase-3 was also involved in apoptosis induced by TNF- $a$ stimulus in our experimental condition. We treated transfected cells with selective caspase-3 inhibitor (Z-DEVD-fmk) $60 \mathrm{~min}$ before TNF- $a$ stimulation. After $72 \mathrm{~h}$, cells were analysed by FACS 
a

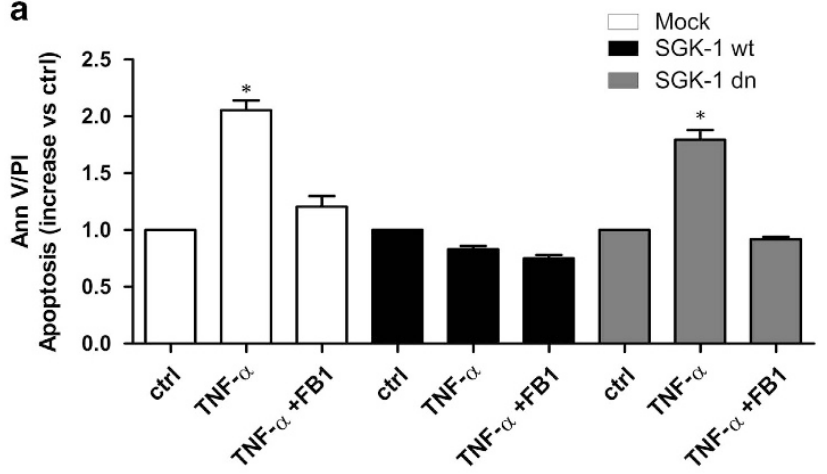

b

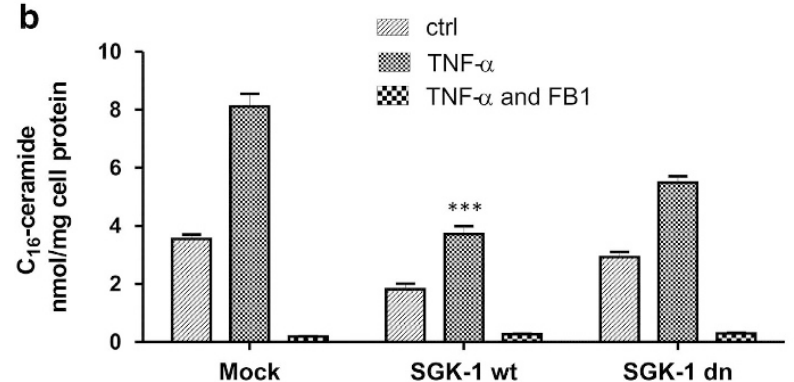

Figure 5 Effect of TNF- $\alpha$ on protection mediated by SGK-1. HEK-293 cells were transfected with Mock, SGK-1wt and SGK-1dn constructs. The cells were treated with TNF- $\alpha(100 \mathrm{ng} / \mathrm{ml})$ for $72 \mathrm{~h}$ in the presence or absence of $100 \mu \mathrm{M}$ FB1 (FumonisinB1) to inhibit ceramide production. FACS analysis as representative histogram of apoptosis versus ctrl (a), ${ }^{*} P<0.05$ TNF- $\alpha$ (Mock and SGK-1 dn) versus TNF- $\alpha+\mathrm{FB} 1$ (Mock and SGK-1 dn), ${ }^{*} P<0.05$ TNF- $\alpha$ (Mock and SGK-1 dn) versus TNF- $\alpha$ (SGK-1 $w t) ; N=3$. Sphingolipid long-chain bases $\left(C_{16}\right.$-ceramide) were measured by gas chromatography/mass spectrometry (GC/MS) (b), ${ }^{\star * \star} P<0.0001$ SGK-1wt (TNF- $\alpha$ ) versus Mock (TNF- $\alpha$ ) and SGK-1dn (TNF- $\alpha$ ); $N=3$. Results are expressed as means \pm S.D.

(Supplementary Figure S1). TNF- $a$ induced greater levels of apoptosis in Mock and in SGK-1dn cells compared with control $(P<0.05)$, while lower apoptotic stimulus was present in SGK-1wt cells (Figure 7a). Treatment with Z-DEVD-fmk significantly reduced numbers of apoptotic cells either in Mock $(P<0.01)$ and in SGK-1dn $(P<0.02)$ (Figure 7a). No effect of Z-DEVD-fmk was present in SGK-1wt cells as the apoptotic stimulus induced by TNF- $a$ was counteracted by SGK-1 (Figure 7a). These data confirmed the role of caspase pathways activation in apoptosis mediated by ceramide, and the protective role of SGK-1 in response to these stimuli, which induce ceramide production.

As previously introduced, PARP-1 is also a caspase-3's substrate in the apoptotic pathway. In our model, we demonstrated higher levels of PARP-1 cleavage after treatment with TNF- $a$ in Mock and SGK-1dn cells, which was abolished with caspase-3 inhibitor. Representative WB images are reported in Figures $7 \mathrm{~b}$ and $\mathrm{d}$. This effect was significantly $(P<0.05)$ reduced in the SGK-1wt group.

Since the activation of caspase- 3 depends on activation of caspases 8 and 9 through 2 distinct pathways, ${ }^{31}$ we investigated their role in our experimental model of apoptosis. Both caspases 8 and 9, when activated by TNF- $a$ and when blocked by selective inhibitors (Z-IETD and Z-LEHD, respectively), had similar effect in the different transfected cellular groups, with no significant variation among them (Supplementary Figure S5). Therefore, our data confirmed that both intrinsic and extrinsic pathways of apoptosis participating in the activation of caspase-3, and then in the related apoptosis activation.

\section{Discussion}

In the present study, we suggested a protective role of SGK-1 against apoptosis induced by ceramide and TNF- $a$ in kidney cells overexpressing SGK-1. The anti-apoptotic action of active SGK-1, tested by measuring NDRG1 phosphorylation levels, was mediated by reduction of caspases activation (caspases 3, 8 and 9) and inhibition of intrinsic and extrinsic apoptotic pathways in response to TNF- $a$ with reduced levels of PARP-1 cleavage. Moreover, a different response of SGK-1 and AKT-1 following apoptotic insult has been described in this study, identifying biological differences between these two kinases. In Figure 8 is reported the representation of the investigated pathways. The described results propose a novel protective role of SGK-1 against apoptosis induced by ceramide and TNF- $a$, increasing our knowledge in this field, opening new perspectives to counteract cellular and tissue injuries, which are typical of several diseases like diabetes and its complications. ${ }^{10}$

SGK-1 has been shown to regulate different cellular pathways in response to harmful stimuli, including phosphorylation of Foxo3a with its consequent translocation from nucleus to cytoplasm, finally resulting in a reduction of proapoptotic gene transcriptions. ${ }^{32}$ Recently, we demonstrated an increased SGK-1 expression and activity resulted in higher production of NO, inhibition of reactive oxygen species (ROS) synthesis, and lower apoptosis in endothelial cell after hyperglycaemia. ${ }^{19}$ Moreover, in cells overexpressing SGK-1 we found an enhancement in GLUT-1 membrane translocation and $\mathrm{Na}^{+}-\mathrm{K}^{+}$ATPase activity. ${ }^{19}$ These results suggest as in endothelial cells higher SGK-1 activity reduced oxidative stress, improved cell survival and restored insulin-mediated NO production. ${ }^{19}$

Nephropathy represents one of the major complications in diabetes, characterized by apoptosis of renal mesangial cells. $^{33,34}$ Increased expression of SPT (serine palmitoyl transferase), an enzyme involved in ceramide synthesis, was seen in renal tubular epithelial and microvascular endothelial cells, which are the main sites of apoptosis observed in diabetic patients. ${ }^{35}$ When ceramide generation was inhibited using SPT inhibitors and ceramide synthase inhibitors (FB1), a reduction in tubular epithelial cell death was observed. ${ }^{11,36,37}$ In this study, we confirmed the apoptotic action of ceramide in response to TNF- $a$, by inhibiting ceramide synthase. Moreover, we demonstrated a pivotal role of SGK-1 in this process that, when inhibited by using its selective inhibitor, resulted in increased apoptotic levels. Interestingly, previous studies conducted in HEK-293 reported a protective role of SGK-1 against apoptosis induced by hypoxic renal injury, ${ }^{38}$ suggesting that one of the possible mechanisms linked SGK-1 protection versus ischaemia is modulation of erythropoietin production. ${ }^{39}$ We used $\mathrm{C}_{2}$-ceramide and TNF- $a$ as a model of injury more related to metabolic disorders. It is known that both stimuli induce apoptosis by activating the cascade of 


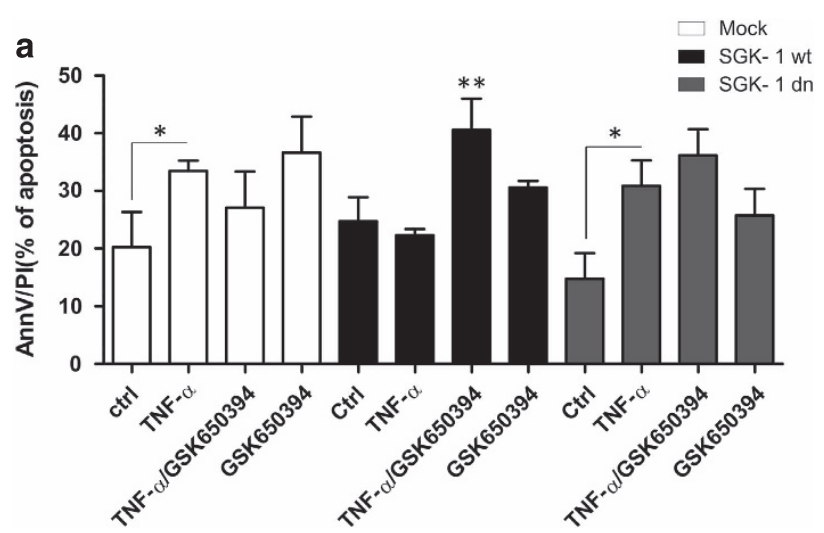

b

SGK-1 wt

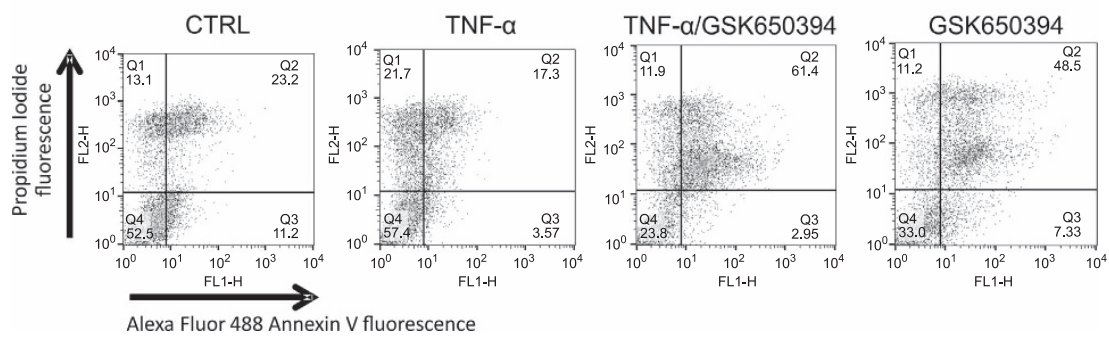

Figure 6 Effect of SGK-1 inhibition on protection against apoptosis. HEK-293 cells were transfected with Mock, SGK-1wt and SGK-1dn constructs and stimulated with SGK-1 inhibitor, GSK650394 $(103 \mathrm{nM}), 60 \mathrm{~min}$ before TNF- $\alpha$ treatment $(100 \mathrm{ng} / \mathrm{ml})$ for $72 \mathrm{~h}$ (a). Apoptotic cells were determined by annexin V-FITC/PI method. These results were obtained from at least three different experiments (a), ${ }^{*} P<0.01$ TNF- $\alpha /$ GSK650394 (SGK-1 wt) versus TNF- $\alpha$ (SGK-1 wt), ${ }^{*} P<0.05$ TNF- $\alpha$ (Mock, SGK-1 dn) versus ctrl (Mock, SGK-1 dn); $N=3$. Results are expressed as means \pm S.D. The plots of (b) show a typical flow-cytometry experiment in SGK-1 wt constructs (b)

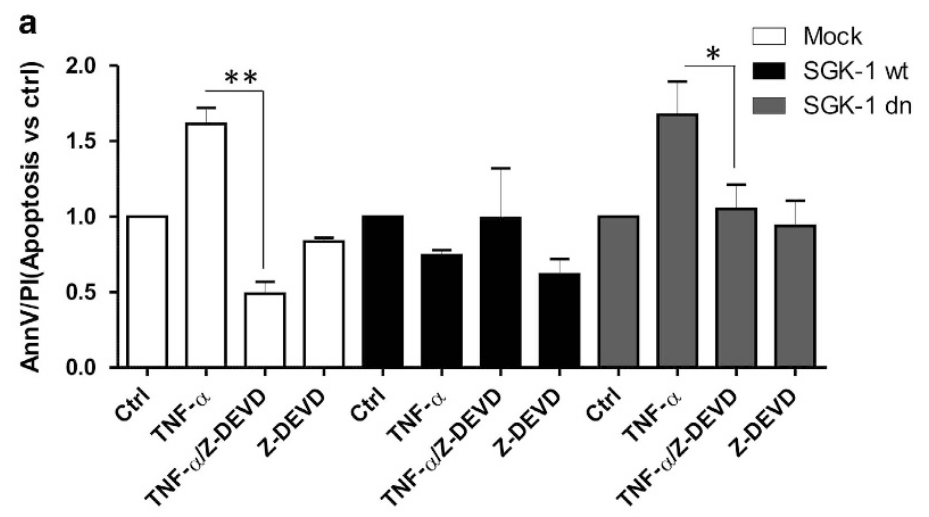

b



C

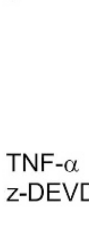

d

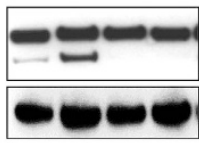

$\begin{array}{ccc}-++ & \text { TNF- } \alpha \\ - & + & + \\ - & + & \text { Z-DEVD }\end{array}$

SGK-1 wt

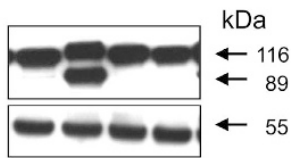

SGK-1 dn

Figure 7 Apoptosis induced by TNF- $\alpha$ is mediated via caspase-3 activation. HEK-293 cells were transfected with Mock, SGK-1wt and SGK-1dn constructs and stimulated with caspase-3 inhibitor, Z-DEVD-FMK, $(20 \mu \mathrm{M}), 60 \mathrm{~min}$ before TNF- $\alpha$ treatment $(100 \mathrm{ng} / \mathrm{ml})$ for $72 \mathrm{~h}$. Apoptotic cells were determined by annexin V-FITC/PI method (a). After $72 \mathrm{~h}$ of treatment with TNF- $\alpha$, the cells were immunoblotted with specific antibodies for full-length (116 KDa) and cleaved PARP-1 (89 KDa). Tubulin was used as a loading control. Blots shown are representative of three independent experiments $(\mathbf{b}-\mathbf{d})$. These results were obtained from at least three different experiments, ${ }^{\star *} P<0.01 \mathrm{TNF}-\alpha$ versus TNF- $\alpha / Z-D E V D$ (Mock), ${ }^{*} P<0.02$ TNF- $\alpha$ versus TNF- $\alpha / Z-D E V D$ (SGK-1 dn); $N=3$. Results are expressed as means \pm S.D. 


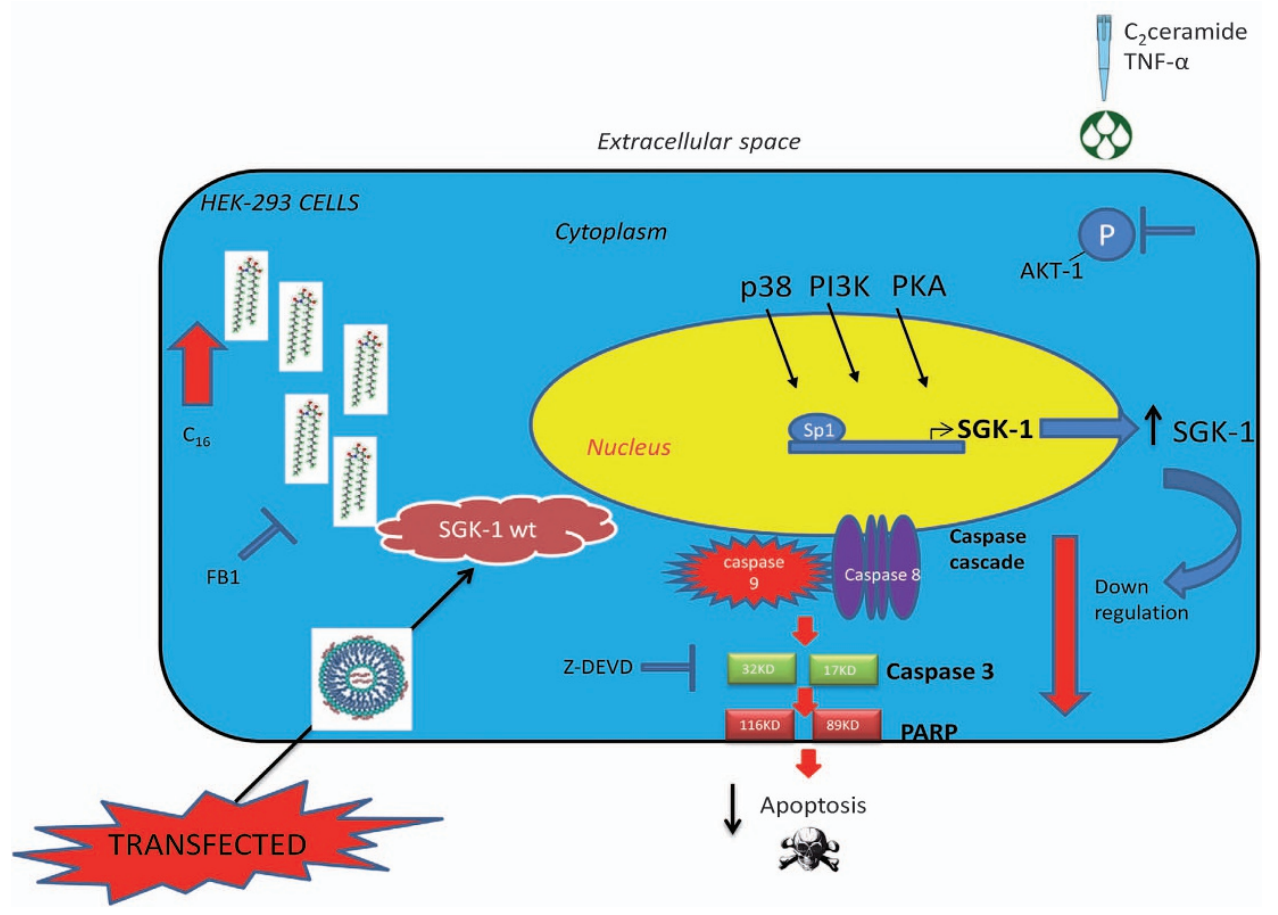

Figure 8 Schematic diagram of pathways activated by ceramide and TNF- $\alpha$ inducing SGK-1 activation and protection against apoptosis. $C_{16}: C_{16}$-ceramide, FB1: fumonisin B1, HEK-293: human embryonic kidney, PI3K: phosphatidylinositide 3-kinases, PKA: protein kinase A, p38: P38 mitogen-activated protein kinases, PARP: poly (ADP-ribose) polymerase, SGK-1 wt: serum and glucocorticoid inducible protein kinase wild type, Z-DEVD: caspase-3 inhibitor

caspases and their substrates. ${ }^{40-44}$ We demonstrated that overexpression and activation of SGK-1 reduced the cleavage of caspase-3 after $\mathrm{C}_{2}$-ceramide stimulus and inactivation of caspase- 3 substrate (PARP-1), protecting against apoptosis. We showed, for the first time, a direct relationship between SGK-1 and caspase's cascade. Particularly, by inhibiting specific pathways, we reported a direct effect of caspase-3 in SGK-1-mediated cellular protection. We also established, after TNF- $a$ treatment, using selective caspase inhibitors, that both initiator caspases 8 and 9 have a principal role in activation of apoptosis in response to TNF- $a$. It is possible to speculate that intrinsic and extrinsic pathways are triggered, as caspase- 9 is activated because of mitochondrial damage and cytochrome $\mathrm{C}$ release and caspase- 8 is activated by death receptors to initiate the extrinsic pathway of apoptosis. ${ }^{14}$ In agreement with our data, it was reported that an increase in SGK-1 was protective in neurons against traumatic brain injury by GSK3 $\beta / \beta$-catenin pathway, which ultimately leaded to inhibition of caspase-3 activation. ${ }^{45}$

Among mechanisms mediated by increased ceramide production, the inhibition of AKT-1, a powerful promoter of cell survival, can partly explain the pro-apoptotic actions of ceramide. ${ }^{11}$ Furthermore, AKT-1 is a principal substrate in the pathways linking insulin to expression, action and subcellular distribution of nutrient transporters. ${ }^{46}$ Indeed, higher production of ceramide can increase insulin resistance through different mechanisms and modulate the pathogenesis of diabetes. ${ }^{47,48}$ Since now, the role of SGK-1 in the regulation of these actions was unclear, although its high homology with AKT-1. Indeed, in response to ceramide we found an increased activation and expression of SGK-1, but differently a reduced activation and expression of AKT-1, demonstrating a different role of these kinases. $\mathrm{C}_{2}$-ceramide has been already shown to decrease activation of AKT-1 increasing apoptosis in neurons. ${ }^{49}$ In fact, several findings suggest the protective role of AKT-1 against apoptosis and constitutive active AKT-1 can inhibit caspases 9 and 3 by post-translational modifications. ${ }^{50}$ We may speculate that differences in the protective response between SGK-1 and AKT-1 could be tissue specific, mediated and dependent on the characteristics of the noxious stimulus, in a compensatory mechanism. In agreement with this hypothesis, the different action of ceramide on SGK-1 and AKT-1 may be, at least in part, dependent on the absence of pleckstrin homology $(\mathrm{PH})$ domains in SGK-1, which is pivotal for the interaction of PDK-1 and AKT-1 with plasma membrane phosphoinositides, modulating its activation. ${ }^{21,47}$ Further studies are needed to investigate these assumptions.

Differential expression of SGK-1 at the cellular and subcellular levels contributes to signalling specificity. ${ }^{51}$ An excessive SGK-1 expression and activity has been shown to participate in different manner in the pathophysiology of several disorders. ${ }^{51}$ Indeed, the role of SGK-1 in inducing protection is pretty controversial and debated. In kidney, SGK-1 assumes distinct roles in regulating $\mathrm{Na}^{+}$and $\mathrm{K}^{+}$ transport through the activation of epithelial $\mathrm{Na}^{+}$channel (ENaC) opening, $\mathrm{Na}^{+}-\mathrm{K}^{+}$-ATPase and $\mathrm{K}^{+}$channels including ROMK, mainly in principal cells of distal tubules, which are sensitive to aldosterone. SGK-1 levels can augment in response to aldosterone increasing kidney $\mathrm{Na}^{+}$reabsorption and $\mathrm{K}^{+}$excretion and therefore affecting blood pressure. ${ }^{52}$ In agreement with these studies, we showed SGK-1-mediated 
$\mathrm{Na}^{+}$regulation in HUVEC. ${ }^{19}$ Currently, to clarify the pathophysiological role of SGK-1, pharmacological inhibitors of SGK-1 could be pivotal to reveal utility of this kinase as a therapeutic target.

Several are the pathways regulating the activity of SGK-1. ${ }^{53}$ Among those, the most important are cAMP/PKA, p38MAPK and PI3K pathways, which when activated increase SGK-1 cellular levels, ${ }^{53,54}$ as further demonstrated by the results of the present study. Interesting, SB202190 by blocking p38MAPK can regulate SGK-1 expression at transcriptional level, probably by binding Sp1 transcription factor to SGK-1 promoter (Figure 8). ${ }^{25,26}$ Among all tested inhibitors, LY294002 had the greater effect on the expression of SGK-1, suggesting as the PI3K pathway deserves further investigation. We also used SGK-1 selective inhibitor (GSK650394) to test the cellular reaction in response to apoptotic stimuli after direct inhibition of SGK-1 kinase activity. The inhibition of SGK-1 resulted in higher levels of cellular death. Our data are in line with previous reports showing higher insulin resistance and cellular damage in cortical collecting duct cells treated with GSK650394. ${ }^{55}$

These results and our previous study ${ }^{19}$ suggest a protective role of SGK-1 in kidney and endothelial cells by different cellular mechanisms. The translation of our results in human by testing the effect of specific SGK-1 modulators could be of great interest since genetic variants of SGK-1 have been already found associated with risk of hypertension ${ }^{56}$ and T2D. ${ }^{57}$ Moreover, a specific SGK-1 polymorphism (rs9493857) has been suggested to be one of the ancestral allele associated with different responses to stress in humans. ${ }^{58}$ Therefore, different SGK-1 genetic variants may code for different type of kinases with higher or lower predisposition to be ubiquitinated and then inactivated, based on their amino acidic sequences, and therefore with different abilities to respond to noxious stimuli.

Strengths of the present study include well-established experimental models by the use of specific cellular constructs, which allow investigating different levels and activities of the kinase. We also employed selective inhibitors for SGK-1 and for the cellular pathways involved in its expression and regulation. Moreover, to our knowledge, we are the first demonstrating the SGK-1 protection against apoptosis mediated by both hexogen and endogen ceramide. We have to acknowledge some limitations for this study. Although overexpressed the kinase still undergo to the ubiquitination process and therefore we are not able to fully control the exact levels of SGK-1 after stimulation. However, this mechanism, even if recognized as a limitation, mimics the physiological cellular process. Other limitations can be, in general, associated with the use of experimental in vitro models that are artificial non-physiological conditions. The employment of SGK-1 knockdown would have been strongly strengthen the conclusion of this paper. However, previous evidence already demonstrated as siSGK-1 leads to enhancement of apoptosis in different conditions. ${ }^{59,60}$

In conclusion, in the present study, we demonstrated as overexpression of SGK-1 kinase is protective against apoptotic insult induced by ceramide in kidney cells. Since aberrant ceramide accumulation in peripheral tissues contributes to the development of pathological clinical manifestations associated with diseases such as diabetes mellitus, obesity, insulin resistance, atherosclerosis and hypertension, ${ }^{61}$ an important future therapeutic strategy could be to develop inhibitors of ceramide action. Therefore, further studies are needed to better define the therapeutic role of SGK-1 in this field.

\section{Materials and Methods}

Cell culture. HEK-293 cells were cultured in Dulbecco's Modified Eagle's Medium supplemented with $100 \mathrm{U} / \mathrm{ml}$ penicillin/streptomycin (Invitrogen, Milan, Italy) and $10 \%$ fetal bovine serum (Invitrogen). Cells were propagated at $37^{\circ} \mathrm{C}$ in humidified air containing $5 \% \mathrm{CO}_{2}$ in $75 \mathrm{~cm}^{2}$ culture flasks and subcultured when the cells reached $70-80 \%$ confluence (every $2-3$ days).

Plasmid constructs. SGK-1wt (EcoRI, Xbal) and SGK-1 dominant negative (dn) (Asp222Ala) (BAMHI, Notl) were cloned in the expression vector pcDNA3 (Clontech, Saint-Germain-en-Laye, France).

Plasmid transfection. HEK-293 cells were plated in $100 \mathrm{~mm}$ culture vessel and at $50-90 \%$ of confluence were transfected with expression plasmids pcDNA3 Myc-SGK-1wt, pcDNA3 Myc-SGK-1dn or pcDNA3 empty vector (Mock) constructs ( $4 \mu \mathrm{g} /$ plate) using LipofectAMINE PLUS (Life Technologies, Milan, Italy) following the manufacturer's instructions. For stable expression, the cells were selected with genetycin G418 $400 \mu \mathrm{g} / \mathrm{ml}$. Several weeks of selection were required for stable expression

Protein extraction and western blot analysis. HEK-293 cells, incubated with the different experimental conditions, were collected and lysed. Proteins were extracted with lysis buffer $\mathrm{pH} 7.2$ containing EDTA $5 \mathrm{mM}$, sodium orthovanadate $2 \mathrm{mM}$, NaF $100 \mathrm{mM}$, NaPP $5 \mathrm{mM}$, Tris-HCl pH 7.6, $50 \mathrm{mM}$, Triton $1 \%$, PMSF $1 \mathrm{mM}$ and complete protease inhibitor $25 \mathrm{X}$ (Roche, Basel, Switzerland). Lysate was sonicated for $10 \mathrm{~s}$ and centrifuged for $30 \mathrm{~min}$ at 13000 r.p.m. $/ 4^{\circ} \mathrm{C}$. The protein concentrations were quantified using Bradford protein assay according to the manufacturer's instructions. For WB analysis, an equal amount of proteins $(100 \mu \mathrm{g})$ was loaded on $10 \%$ SDS-polyacrylamide gel and transferred onto a nitrocellulose membrane (Millipore, Darmstadt, Germany) by electroblotting. After $1 \mathrm{~h}$ of blocking with $5 \%$ milk, the blots were probed and incubated with the specific antibodies overnight at $4{ }^{\circ} \mathrm{C}$. Then, blots were treated with diluted enzyme-linked secondary antibodies, and visualized by enhanced chemioluminescence (ECL-PE, Amersham, Chalfont Saint Giles, UK) according to the manufacturer's procedure. Primary antibodies used were polyclonal anti-PARP-1 (89 and $116 \mathrm{KDa}$ ), anti-rabbits, $1: 1000$ in WB (Cell Signalling, Danvers, MA, USA), polyclonal anti-SGK-1 $(50 \mathrm{kDa})$ anti-rabbits, 1:1000 in WB (UpState in Millipore), polyclonal anti-AKT-1, $(60 \mathrm{kDa})$ anti-rabbits, $1: 1000$ in WB (Cell Signalling), polyclonal p-AKT-1 (Ser 473) $(60 \mathrm{kDa})$, anti-rabbits, $1: 1000$ in WB (Cell Signalling), monoclonal anticaspase-3 (clone 4-1-1-18) (32 and 17 KDa) anti-mouse 1: 1000 in WB (UpState in Millipore), monoclonal anti-tubulin (clone DM 1 A) (55 kDa) anti-mouse 1: 10000 in WB (Sigma, Milan, Italy), anti-p-NDRG1 (Thr346 and Ser 330) (46-48 kDa) antirabbits, 1: 1000 in WB (Cell Signalling).

Cell treatments. Insulin (Sigma): $10^{-7} \mathrm{M}$ for $30 \mathrm{~min}$. $C_{2}$-Ceramide $/ C_{6^{-}}$ ceramide/ $\mathrm{C}_{2}$-Dihydroceramide (BIOMOL in Enzo Life Science, Farmingdale, NY, USA): dissolved in DMSO (vehicle), then diluted into serum-free DMEM at the indicated concentrations and briefly sonicated, concentration used in the experiment is $50 \mu \mathrm{M}$, in serum-free medium in $0.1 \%$ BSA RIA Grade (Sigma) for $48 \mathrm{~h}$. TNF- $\alpha$ (Sigma): $100 \mathrm{ng} / \mathrm{ml}$ for $72 \mathrm{~h}$. FumonisinB1 (Cayman Chemical Company, Ann Arbor, MA, USA): $100 \mu \mathrm{M}, 30 \mathrm{~min}$ before the stimulation with TNF- $\alpha$. LY294002 (Calbiochem, San Diego, CA, USA): $30 \mu \mathrm{M}, 30$ min before the stimulation with insulin, $\mathrm{C}_{2}$-ceramide or $\mathrm{C}_{2}$-Dihydroceramide. SB202190, H-89 (Calbiochem): $10 \mu \mathrm{M}, 30$ min before the stimulation with insulin, $\mathrm{C}_{2}$-ceramide or $\mathrm{C}_{2}$-Dihydroceramide. GSK650394 (Tocris, Bristol, UK): $103 \mathrm{nM}, 60 \mathrm{~min}$ before the TNF- $\alpha$ stimulation. Z-DEVD-fmk (BD Pharmingen, Milan, Italy): $20 \mu \mathrm{M}, 60 \mathrm{~min}$ before the TNF- $\alpha$ stimulation.

DNA ladder analysis. HEK-293 cells were transfected with expression plasmids pcDNA3 Myc-SGK-1wt, pcDNA3 Myc-SGK-1dn and pcDNA3 empty vector constructs, after $24 \mathrm{~h}$ were stimulated with $\mathrm{C}_{2}$-ceramide or 
$\mathrm{C}_{2}$-dihydroceramide for $48 \mathrm{~h}$. Then, cells were collected and lysed in $10 \mathrm{mM} \mathrm{NaCl}$, $100 \mathrm{mM}$ EDTA, 1\% SDS and $200 \mathrm{mM}$ Tris- $\mathrm{HCl}$ pH 8.5 buffer. Lysates were treated for $2 \mathrm{~h}$ at $60^{\circ} \mathrm{C}$ with $100 \mu \mathrm{g} / \mathrm{ml}$ proteinase $\mathrm{K}$. Then, samples were centrifuged at 13000 r.p.m. for $15 \mathrm{~min}$ at $4^{\circ} \mathrm{C}$, supernatants were transferred to a new tube and treated with RNase-DNase free $100 \mu \mathrm{g} / \mathrm{ml}$ at $50^{\circ} \mathrm{C}$ for $40 \mathrm{~min}$. The DNA was extracted by phenol/chloroform (1:1). DNA was separated through $1.5 \%$ agarose gel and stained with ethidium bromide (EtBr, Sigma). Finally, DNA fragmentation pattern was visualized by ultraviolet light source.

Flow-cytometry analysis for measurement of sub-G1 phase. Apoptotic cell nuclei were detected in HEK-293 cells by flow cytometry. Briefly, cells were harvested, centrifuged at 1000 r.p.m. for $5 \mathrm{~min}$ and washed twice with $0.5 \mathrm{ml}$ of PBS. Then, cell lysates were gently resuspended in $0.5 \mathrm{ml}$ propidium iodide (PI) hypotonic solution ( $50 \mu \mathrm{g} / \mathrm{ml}$ in $0.1 \%$ sodium citrate added in $0.1 \%$ Triton-X 100) (Sigma) and incubated for $15 \mathrm{~min}$ in darkness. The fluorescence emitted from PI-DNA complex was quantified after laser excitation $(488 \mathrm{~nm})$ using a FACScalibur (Becton Dickinson, Milan, Italy) and data were analysed by BD-CellQuest software (Milan, Italy). Experiments were carried out on about 10000 cells and repeated 3-5 times.

Fluorescence-activated cell Sorter analysis using AnnexinV/PI Staining. A total of $5 \times 10^{5}$ cells were harvested and washed with PBS. To detect apoptotic changes in the position of phosphatidylserine, annexin $\mathrm{V}$ binding assay was performed using the Annexin V-FITC/PI apoptosis detection kit (BD Pharmingen) according to the manufacturer's protocol. The procedure consists of the binding of annexin V-FITC to phosphatidylserine in the membrane of cells, which are beginning the apoptotic process, and the binding of PI to the cellular DNA in cells where the cell membranes were been totally compromised. The cells are incubated with annexin V-FITC and PI. After $10 \mathrm{~min}$ of incubation at room temperature, cells were analysed by flow cytometry. Annexin V-FITC was detected as a green fluorescence and PI is detected as a red fluorescence. Ten thousand events generally were monitored, and data analysis was performed using BD-Cell Quest software.

Ceramide and sphingomyelin species analysis in HEK 293 cells. Simultaneous identification of ceramide and sphingomyelin species was performed by gas chromatography/mass spectrometry (GC/MS). Separation of ceramide from sphingomyelin species was obtained by 'on-injector' thermal cracking of trimethylsilyl (TMS)-derivatized sphingolipids as described by others ${ }^{62}$ with some modifications. Briefly, cultured cells were scraped in cold PBS and sonicated. Cell proteins content was assayed and $5 \mu \mathrm{g}$ of internal standard (IS) (C ${ }_{17}$ CER, C17:0 S18:1) was added to $250 \mu \mathrm{g}$ of cell lysate. Lipids were extracted according to Bligh and Dyer ${ }^{62}$ and TMS derivatized by incubating overnight the lipid extract with $25 \mu \mathrm{l}$ of a BSTFA (1\% trimethylchlorosilane, TMCS)-acetonitrile $(1: 1 \mathrm{v} / \mathrm{v})$ mixture. Two microliters of sample were injected on a HP1313 low-polarity column (Agilent Technologies, Santa Clara, CA, USA) in a Agilent HP5890 gas chromatograph under the following conditions: injector temperature: $310^{\circ} \mathrm{C}$; oven: starting at $225^{\circ} \mathrm{C}$ for $1 \mathrm{~min}$, then the temperature increased to $325^{\circ} \mathrm{C}$ at $5{ }^{\circ} \mathrm{C} / \mathrm{min}$ and remained stable for $10 \mathrm{~min}$. The $\mathrm{m} / \mathrm{z}$ ratios were collected by an Agilent HP5973N mass spectrometer in single ion monitoring (SIM) mode. The $311 \mathrm{~m} / \mathrm{z}$ could be used as the measuring ion since it exhibited the best peak purity as demonstrated by injecting increasing amount of a standard mixture spiked on a cell matrix (data not shown). The 370 and $311 \mathrm{~m} / \mathrm{z}$ ratios were used for the absolute quantification of the $\mathrm{C}_{16^{-}}$ceramide. A calibration curve was built by spiking cell lysate replicates, obtained from a large pool, with $5 \mu \mathrm{g}$ of IS and increasing amounts of true $\mathrm{C}_{16^{-}}$ ceramide standard (Avanti Polar Lipids, Alabaster, AL, USA). $\mathrm{C}_{16}$-ceramide curve was highly linear (Pearson $R>0.99$ ) between 0.3 and $5 \mu \mathrm{g} / \mathrm{l}$ of injected ceramide (data not shown). All standards and reagents other than indicated were purchased from Sigma-Aldrich (St Louis, MO, USA).

Microscope images. Cell images were performed by a microscope Nikon Eclipse TE-2000S (Nikon, Florence, Italy) equipped with a cool-snap camera (see Supplementary Information).

Statistical analysis. Each experiment was repeated at least three times with reproducible results consistently. Data are expressed as mean \pm S.D. of combined results from three independent experiments. Statistical analysis was performed using one-way ANOVA test followed by the post hoc test of Newman-Keuls or with the unpaired $t$-test. Differences at $P<0.05$ were considered as statistically significant.

\section{Conflict of Interest}

The authors declare no conflict of interest.

Acknowledgements. This work has been supported by following grants Research Project 2009 grant, Fondazione Roma; PRIN 2010 and 2011 grants from the Ministero dell'Istruzione, dell'Università e della Ricerca (to DL and PS); Fondazione Umberto Di Mario, Rome, Italy; ASI N. 2013-085-R.0 (Italian Space Agency); European Social Fund, under the Italian Ministry of Education, University and Research PON03PE_00146_1/10 BIBIOFAR. All authors approve this submission and do not have any conflict of interest with any third party related to this work. We would like to thank Dr. Graziano Bonelli for the technical assistance in preparing figures for this article.

1. Sanchez-Nino MD, Benito-Martin A, Ortiz A. New paradigms in cell death in human diabetic nephropathy. Kidney Int 2010; 78: 737-744.

2. Kim NH, Kim K, Park WS, Son HS, Bae Y. PKB/Akt inhibits ceramide-induced apoptosis in neuroblastoma cells by blocking apoptosis-inducing factor (AIF) translocation. J Cell Biochem 2007; 102: 1160-1170.

3. Kim SW, Kim HJ, Chun YJ, Kim MY. Ceramide produces apoptosis through induction of p27 (kip1) by protein phosphatase 2A-dependent Akt dephosphorylation in PC-3 prostate cancer cells. J Toxicol Environ Health A 2010; 73: 1465-1476.

4. Samadi A. Ceramide-induced cell death in lens epithelial cells. Mol Vis 2007; 13: 1618-1626.

5. Chatterjee M, Wu S. Cell line dependent involvement of ceramide in ultraviolet light-induced apoptosis. Mol Cell Biochem 2001; 219: 21-27.

6. Dbaibo GS, El-Assaad W, Krikorian A, Liu B, Diab K, Idriss NZ et al. Ceramide generation by two distinct pathways in tumor necrosis factor alpha-induced cell death. FEBS Lett 2001; 503: 7-12.

7. Suzuki J, Akahane K, Nakamura J, Naruse K, Kamiya H, Himeno T et al. Palmitate induces apoptosis in Schwann cells via both ceramide-dependent and independent pathways. Neuroscience 2011; 176: 188-198.

8. Ghosh N, Patel N, Jiang K, Watson JE, Cheng J, Chalfant CE et al. Ceramide-activated protein phosphatase involvement in insulin resistance via Akt, serine/arginine-rich protein 40, and ribonucleic acid splicing in L6 skeletal muscle cells. Endocrinology 2007; 148: 1359-1366.

9. Samad F, Hester KD, Yang G, Hannun YA, Bielawski J. Altered adipose and plasma sphingolipid metabolism in obesity: a potential mechanism for cardiovascular and metabolic risk. Diabetes 2006; 55: 2579-2587.

10. Straczkowski M, Kowalska I, Baranowski M, Nikolajuk A, Otziomek E, Zabielski P et al. Increased skeletal muscle ceramide level in men at risk of developing type 2 diabetes. Diabetologia 2007; 50: 2366-2373.

11. Galadari S, Rahman A, Pallichankandy S, Galadari A, Thayyullathil F. Role of ceramide in diabetes mellitus: evidence and mechanisms. Lipids Health 12: 98.

12. Pettus BJ, Chalfant CE, Hannun YA. Ceramide in apoptosis: an overview and current perspectives. Biochim Biophys Acta 2002; 1585: 114-125.

13. Mcllwain DR, Berger T, Mak TW. Caspase functions in cell death and disease. Cold Spring Harb Perspect Biol 2013; 5: a008656.

14. Li J, Yuan J. Caspases in apoptosis and beyond. Oncogene 2008; 27: 6194-6206.

15. Kim MY, Zhang T, Kraus WL. Poly(ADP-ribosyl)ation by PARP-1: 'PAR-laying' NAD+ into a nuclear signal. Genes Dev 2005; 19: 1951-1967.

16. Waldegger S, Barth $P$, Raber G, Lang F. Cloning and characterization of a putative human serine/threonine protein kinase transcriptionally modified during anisotonic and isotonic alterations of cell volume. Proc Natl Acad Sci USA 1997; 94: 4440-4445.

17. Firestone GL, Giampaolo JR, O'Keeffe BA. Stimulus-dependent regulation of serum and glucocorticoid inducible protein kinase (SGK) transcription, subcellular localization and enzymatic activity. Cell Physiol Biochem 2003; 13: 1-12.

18. Musch MW, Lucioni A, Chang EB. Aldosterone regulation of intestinal Na absorption involves SGK-mediated changes in NHE3 and Na+ pump activity. Am J Physiol Gastrointest Liver Physiol 2008; 295: G909-G919.

19. Ferrelli F, Pastore D, Capuani B, Lombardo MF, Blot-Chabaud M, Coppola A et al. Serum glucocorticoid inducible kinase (SGK)-1 protects endothelial cells against oxidative stress and apoptosis induced by hyperglycaemia. Acta Diabetol 2015; 52: 55-64.

20. Boini KM, Hennige AM, Huang DY, Friedrich B, Palmada M, Boehmer C et al. Serum- and glucocorticoid-inducible kinase 1 mediates salt sensitivity of glucose tolerance. Diabetes 2006; 55: 2059-2066.

21. Tessier M, Woodgett JR. Serum and glucocorticoid-regulated protein kinases: variations on a theme. J Cell Biochem 2006; 98: 1391-1407.

22. Murray JT, Campbell DG, Morrice N, Auld GC, Shpiro N, Marquez R et al. Exploitation of KESTREL to identify NDRG family members as physiological substrates for SGK1 and GSK3. Biochem J 2004; 384: 477-488.

23. Sakoda H, Gotoh Y, Katagiri H, Kurokawa M, Ono H, Onishi Y et al. Differing roles of Akt and serum- and glucocorticoid-regulated kinase in glucose metabolism, DNA synthesis, and oncogenic activity. J Biol Chem 2003; 278: 25802-25807. 
24. Perrotti N, He RA, Phillips SA, Haft CR, Taylor SI. Activation of serum- and glucocorticoidinduced protein kinase (Sgk) by cyclic AMP and insulin. J Biol Chem 2001; 276: 9406-9412

25. Leong ML, Maiyar AC, Kim B, O'Keeffe BA, Firestone GL. Expression of the serum- and glucocorticoid-inducible protein kinase, Sgk, is a cell survival response to multiple types of environmental stress stimuli in mammary epithelial cells. J Biol Chem 2003; 278 5871-5882.

26. Bell LM, Leong ML, Kim B, Wang E, Park J, Hemmings BA et al. Hyperosmotic stress stimulates promoter activity and regulates cellular utilization of the serum- and glucocorticoid-inducible protein kinase (Sgk) by a p38 MAPK-dependent pathway. J Biol Chem 2000; 275: 25262-25272.

27. Stratford S, Hoehn KL, Liu F, Summers SA. Regulation of insulin action by ceramide: dual mechanisms linking ceramide accumulation to the inhibition of Akt/protein kinase B. J Biol Chem 2004; 279: 36608-36615.

28. Grigsby RJ, Dobrowsky RT. Inhibition of ceramide production reverses TNF- $\alpha$ induced insulin resistance. Biochem Biophys Res Commun 2001; 287: 1121-1124.

29. Teruel T, Hernandez R, Lorenzo M. Ceramide mediates insulin resistance by tumor necrosis factor-alpha in brown adipocytes by maintaining Akt in an inactive dephosphorylated state. Diabetes 2001; 50: 2563-2571.

30. Sherk AB, Frigo DE, Schnackenberg CG, Bray JD, Laping NJ, Trizna W et al. Development of a small-molecule serum- and glucocorticoid-regulated kinase-1 antagonist and its evaluation as a prostate cancer therapeutic. Cancer Res 2008; 68: 7475-7483.

31. Goc A, Kochuparambil ST, Al-Husein B, Al-Azayzih A, Mohammad S, Somanath PR. Simultaneous modulation of the intrinsic and extrinsic pathways by simvastatin in mediating prostate cancer cell apoptosis. BMC Cancer 2012; 12: 409.

32. Brunet A, Park J, Tran H, Hu LS, Hemmings BA, Greenberg ME. Protein kinase SGK mediates survival signals by phosphorylating the forkhead transcription factor FKHRL1 (FOXO3a). Mol Cell Biol 2001; 21: 952-965.

33. Lin CL, Wang JY, Huang YT, Kuo YH, Surendran K, Wang FS. Wnt/beta-catenin signaling modulates survival of high glucose-stressed mesangial cells. J Am Soc Nephrol 2006; 17 : 2812-2820.

34. Mishra R, Emancipator SN, Kern T, Simonson MS. High glucose evokes an intrinsic proapoptotic signaling pathway in mesangial cells. Kidney Int 2005; 67: 82-93.

35. Liu G, Han F, Yang Y, Xie Y, Jiang H, Mao Y et al. Evaluation of sphingolipid metabolism in renal cortex of rats with streptozotocin-induced diabetes and the effects of rapamycin. Nephrol Dial Transplant 2011; 26: 1493-1502.

36. Itoh Y, Yano T, Sendo T, Sueyasu M, Hirano K, Kanaide $\mathrm{H}$ et al. Involvement of de novo ceramide synthesis in radiocontrast-induced renal tubular cell injury. Kidney Int 2006; 69: 288-297.

37. Basnakian AG, Ueda N, Hong X, Galitovsky VE, Yin X, Shah SV. Ceramide synthase is essential for endonuclease-mediated death of renal tubular epithelial cells induced by hypoxia-reoxygenation. Am J Physiol Renal Physiol 2005; 288: F308-F314.

38. Rusai K, Wagner B, Roos M, Schmaderer C, Strobl M, Boini KM et al. The serum and glucocorticoid-regulated kinase 1 in hypoxic renal injury. Cell Physiol Biochem 2009; 24 577-584.

39. Rusai K, Prokai A, Szebeni B, Fekete A, Treszl A, Vannay A et al. Role of serum and glucocorticoid-regulated kinase-1 in the protective effects of erythropoietin during rena ischemia/reperfusion injury. Biochem Pharmacol 2010; 79: 1173-1181.

40. Movsesyan VA, Yakovlev AG, Dabaghyan EA, Stoica BA, Faden Al. Ceramide induces neuronal apoptosis through the caspase-9/caspase-3 pathway. Biochem Biophys Res Commun 2002; 299: 201-207.

41. Stoica BA, Movsesyan VA, Lea PMt, Faden Al. Ceramide-induced neuronal apoptosis is associated with dephosphorylation of Akt, BAD, FKHR, GSK-3beta, and induction of the mitochondrial-dependent intrinsic caspase pathway. Mol Cell Neurosci 2003; 22: 365-382.

42. Minano A, Caballero-Benitez A, Lluch M, Moran J, Rodriguez-Alvarez J. C2-ceramide mediates cerebellar granule cells apoptosis by activation of caspases-2, -9 , and -3 . J Neurosci Res 2008; 86: 1734-1747.

43. Sethu S, Melendez AJ. New developments on the TNFalpha-mediated signalling pathways. Biosci Rep 2011; 31: 63-76.

44. Fan JH, Feng GG, Huang L, Tang GD, Jiang HX, Xu J. Naofen promotes TNF-alpha-mediated apoptosis of hepatocytes by activating caspase-3 in lipopolysaccharidetreated rats. World J Gastroenterol 2014; 20: 4963-4971.
45. Wu X, Mao H, Liu J, Xu J, Cao J, Gu X et al. Dynamic change of SGK expression and its role in neuron apoptosis after traumatic brain injury. Int J Clin Exp Pathol 2013; 6: 1282-1293.

46. Bikman BT, Summers SA. Ceramides as modulators of cellular and whole-body metabolism. $J$ Clin Invest 2011; 121: 4222-4230.

47. Hajduch E, Turban S, Le Liepvre X, Le Lay S, Lipina C, Dimopoulos N et al. Targeting of PKCzeta and PKB to caveolin-enriched microdomains represents a crucial step underpinning the disruption in PKB-directed signalling by ceramide. Biochem J 2008; 410: 369-379.

48. Powell DJ, Hajduch E, Kular G, Hundal HS. Ceramide disables 3-phosphoinositide binding to the pleckstrin homology domain of protein kinase B (PKB)/Akt by a PKCzeta-dependent mechanism. Mol Cell Biol 2003; 23: 7794-7808.

49. Sanchez-Mora RM, Arboleda H, Arboleda G. PINK1 overexpression protects against C2-ceramide-induced CAD cell death through the PI3K/AKT pathway. J Mol Neurosci 2012; 47: $582-594$

50. Zhou H, Li XM, Meinkoth J, Pittman RN. Akt regulates cell survival and apoptosis at a postmitochondrial level. J Cell Biol 2000; 151: 483-494.

51. Lang $\mathrm{F}$, Stournaras $\mathrm{C}$. Serum and glucocorticoid inducible kinase, metabolic syndrome, inflammation, and tumor growth. Hormones (Athens) 2013; 12: 160-171.

52. Pao AC. SGK regulation of renal sodium transport. Curr Opin Nephrol Hypertens 2012; 21: 534-540.

53. Lang F, Artunc F, Vallon V. The physiological impact of the serum and glucocorticoidinducible kinase SGK1. Curr Opin Nephrol Hypertens 2009; 18: 439-448.

54. Vasquez MM, Castro R, Seidner SR, Henson BM, Ashton DJ, Mustafa SB. Induction of serum- and glucocorticoid-induced kinase-1 (SGK1) by cAMP regulates increases in alpha-ENaC. J Cell Physiol 2008; 217: 632-642.

55. Mansley MK, Wilson SM. Effects of nominally selective inhibitors of the kinases PI3K, SGK1 and PKB on the insulin-dependent control of epithelial $\mathrm{Na}+$ absorption. Br J Pharmacol 2010; 161: $571-588$.

56. Rao AD, Sun B, Saxena A, Hopkins PN, Jeunemaitre X, Brown NJ et al. Polymorphisms in the serum- and glucocorticoid-inducible kinase 1 gene are associated with blood pressure and renin response to dietary salt intake. J Hum Hypertens 2013; 27: 176-180.

57. Schwab M, Lupescu A, Mota M, Mota E, Frey A, Simon P et al. Association of SGK1 gene polymorphisms with type 2 diabetes. Cell Physiol Biochem 2008; 21: 151-160.

58. Luca F, Kashyap S, Southard C, Zou M, Witonsky D, Di Rienzo A et al. Adaptive variation regulates the expression of the human SGK1 gene in response to stress. PLoS Genet 2009; 5. 1000489

59. Nasir O, Wang K, Foller M, Gu S, Bhandaru M, Ackermann TF et al. Relative resistance of SGK1 knockout mice against chemical carcinogenesis. IUBMB Life 2009; 61: 768-776.

60. Dehner M, Hadjihannas M, Weiske J, Huber O, Behrens J. Wnt signaling inhibits Forkhead box O3a-induced transcription and apoptosis through up-regulation of serum- and glucocorticoid-inducible kinase 1. J Biol Chem 2008; 283: 19201-19210.

61. Summers SA, Nelson DH. A role for sphingolipids in producing the common features of type 2 diabetes, metabolic syndrome $X$, and Cushing's syndrome. Diabetes 2005; 54 : 591-602.

62. Bligh EG, Dyer WJ. A rapid method of total lipid extraction and purification. Can J Biochem Physiol 1959; 37: 911-917.

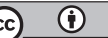

Cell Death and Disease is an open-access journal published by Nature Publishing Group. This work is licensed under a Creative Commons Attribution 4.0 International License. The images or other third party material in this article are included in the article's Creative Commons license, unless indicated otherwise in the credit line; if the material is not included under the Creative Commons license, users will need to obtain permission from the license holder to reproduce the material. To view a copy of this license, visit http://creativecommons.org/licenses/by/4.0/ 